Fecha de recepción: noviembre 2020 Fecha de aprobación: diciembre 2020 Fecha publicación: marzo 2021

\section{Pictura et sequentia: huellas de las bellas artes en la narración figurativa de Antonio Altarriba entre 1977 y $1991^{1}$}

David García-Reyes ${ }^{(1)}$ y

Rubén Romero Santos ${ }^{(2)}$

\begin{abstract}
Resumen: Los primeros años como creador de historietas de Antonio Altarriba son esenciales para entender algunos de los mejores hallazgos narrativos y estéticos del cómic español de finales del siglo XX. Además, la producción de Altarriba entre 1977 y 1991, en colaboración con diversos artistas gráficos, refleja algunas de las obsesiones estéticas y de las huellas de la historia del arte en la producción temprana del autor. Será el inicio de la construcción de un imaginario propio tan fértil como sugerente. Esta investigación rastrea esas citas y amplía el estudio del corpus secuencial de Altarriba, para apuntar algunas de las claves que han contribuido a señalarle como uno de los autores españoles más destacados de la narración gráfica contemporánea.
\end{abstract}

Palabras clave: Antonio Altarriba - cómic - pintura - narración figurativa - Grupo Bustrófedon.

[Resúmenes en inglés y portugués en la página 136]

(1) David García-Reyes (Universidad de Concepción, Chile ${ }^{2}$ - mangarcia@udec.cl)es Licenciado en Historia del Arte (UCM) y Doctor en Literatura Latinoamericana (UdeC). Investigador CONICYT en la Facultad de Humanidades y Artes de la Universidad de Concepción (UdeC, Chile). Ha impartido docencia en Pregrado y Postgrado en España y Chile y sus investigaciones, publicadas en revistas como Alpha, Journal of Geography, Área Abierta, Izquierdas, Archivos de la Filmoteca, etc, giran en torno a las traslaciones filmoliterarias del cine contemporáneo latinoamericano, ocupándose además de los procesos intermediales que confluyen y operan en distintas manifestaciones artísticas, especialmente en el estudio de la novela gráfica y la historieta en el contexto iberoamericano, cuestiones ampliamente tratadas en su producción científica. Es miembro del grupo de investigación Historia e Imaginarios Audiovisuales (UCM).

(2) Rubén Romero Santos (Universidad Carlos III de Madrid³ rrsantos@hum.uc3m.es) es Licenciado en Periodismo y Doctor en Investigación Aplicada a los Medios de Comunicación por la Universidad Carlos III de Madrid (UC3M). Actualmente ejerce como profesor e investigador en el Departamento de Comunicación Audiovidual en la UC3M. Miembro del grupo de investigación Televisión y cine: memoria, representación e industria (TECMERIN). Es autor de La pistola y el corazón. Conversaciones con Agustín Díaz 
Yanes (Cuadernos Tecmerin, 2014). Ha participado en World Film Locations: Barcelona (Intellect, 2013), La ficción audiovisual en España (Gedisa, 2012), Tracing the Borders of Spanish Horror Cinema and Television (Routledge, 2017), Ficcionando en el siglo XXI. La ficción televisiva en España (Fragua, 2015), A New Gaze: Women Creators of Film and Television in Democratic Spain (Cambridge Scholars Publishing, 2015) y Padres y madres en serie (UOC, 2015).

\section{Introducción}

En el ámbito de la historieta iberoamericana, hablar de Antonio Altarriba (Zaragoza, 1952) es señalar a uno de sus principales creadores que, a su labor como guionista, añade la de teórico, crítico, editor, comisario e impulsor de iniciativas vinculadas a la vanguardia del cómic español desde finales de los años setenta. Su figura ha alcanzado un reconocimiento unánime con la novela gráfica El arte de volar (2009) con grafismo de Kim, convirtiéndose en un verdadero acontecimiento editorial. La obra cosecha infinidad de premios en España y en el extranjero, siendo los más destacables el "Premio Nacional de Cómic", otorgado por el Ministerio de Cultura del Gobierno de España (2010) y el "English Pen Award” del Arts Council England (2015). Su éxito convertirá a Altarriba en un autor traducido desde entonces al portugués, al italiano, al inglés, al alemán o al francés. Además, la trayectoria de Altarriba se ha ampliado a los trabajos como guionista de composiciones fotográficas junto a la fotógrafa Pilar Albajar desde finales de los ochenta ${ }^{4}$ y al ejercicio de la literatura, siendo autor de libros de relatos y novelas ${ }^{5}$. A eso debemos sumarle su posición docente como catedrático de Literatura francesa en la Universidad del País Vasco (UPV) desde los 38 años, contribuyendo a difundir el estudio de la historieta y desarrollando una notable producción crítica en torno a la teoría y la historiografía del cómic. Su propia tesis doctoral, La narración figurativa. Acercamiento a la especificidad de un género a partir de la Bande Dessinée de expresión francesa (1981), es una de las primeras leídas y defendidas en España sobre el arte secuencial.

El reconocimiento hacia Altarriba es el fruto de un largo proceso de creación, pero también de reflexión, entre finales de los años setenta y hasta principios de los noventa, y que es el objeto de estudio de esta investigación. Esta primera etapa del guionista en el mundo del cómic puede abordarse desde una lectura intermedial, lo que Irina Rajewsky denominó "transposición de arte" (2005, p. 50), pintura y cómic comparten el empleo del dibujo y ambas aplican el mismo en función del relato narrado (Gasca y Mensuro, 2014, p. 8). Altarriba durante los años 80 va a consolidarse como uno de los creadores más importantes del cómic español y en palabras de Josep Maria Beà, "el más renombrado guionista" del país (Altarriba y Royo, 2011, p. 6). Una fase en la que destaca la permeabilidad que la pintura y el arte occidentales han tenido de uno u otro modo en la forma en la que $\mathrm{Al}$ tarriba ha concebido y proyectado la historieta como autor. Los rasgos fundamentales de esta etapa vendrían precedidos de una vocación experimentalista, en la que Altarriba y los dibujantes con los que trabaja, exploran narrativa y estéticamente caminos expresivos que 
son paralelos a expresiones vanguardistas de la historieta a nivel local y global en esta época, sintonizando con las reflexiones de Bart Beaty (2012), inscritas dentro de la sociología de la cultura, y su aproximación a las relaciones entre la historieta y las bellas artes junto con la legitimación del cómic como objeto artístico. Las inquietudes y aportaciones de Altarriba y de sus ilustradores son sintomáticas de la redefinición del cómic del periodo, y de su capacidad para mostrar la enorme singularidad y la capacidad del arte secuencial en su consolidación como manifestación cultural en su vocación más transgresora. El propio Altarriba en su posición dual como teórico y creador, tiene mucho que ver en los procesos que se generan durante los años ochenta en el panorama historietístico español y, de esta forma, se expresa tempranamente al apuntar que el cómic "eminentemente narrativo, se presenta como un terreno sin explorar, particularmente tentador y fundamentalmente útil para comprobar la validez del método propuesto en un campo distinto al tradicional relato literario" (Altarriba, 1983, p. 10). Años después, Altarriba seguirá manteniendo que "contar historias en imágenes ha sido la primera y principal manera de dejar constancia de nuestra experiencia o de nuestros deseos, en cualquier caso de ese indicio básico de humanidad que es nuestra capacidad de representación simbólica" (Altarriba, 2011, p. 12). La colaboración de Altarriba con dibujantes e ilustradores como Luis Royo, Strader, Ricard Castells, Javier Hernández Landazábal, Samuel Aznar, Rafa Estrada o Patricia Albajar se extiende a lo largo de 1977-1991 y proyecta algunas de las constantes temáticas y estéticas del autor aragonés. Las sinergias y la retroalimentación con cada uno de los creadores con los que trabaja Altarriba, muestran las inquietudes de un imaginario visual que va nutriéndose de numerosas iconografías vinculadas al arte de la pintura, e incluso a otras manifestaciones plásticas que ayudan a analizar el conjunto de la producción del guionista. También denota una clara voluntad de colaboración, haciendo que la creación sea un tránsito entre dos creadores, ya que, según el autor: "en el cómic la dependencia del grafismo condiciona los planteamientos de la narración” (Altarriba, 1983, p. 13). El análisis de la referencialidad artística que se puede estudiar en este primer periodo de la obra secuencial de Altarriba se distingue por estar repleto de una galería de imágenes de las artes que, lejos de tener un carácter anecdótico o casual, nacen de la capacidad del guionista y de los ilustradores para configurar la trama y la escenografía de la misma, encriptando detalles y/o informaciones esenciales para la narración, una composición del escenario ordenada a partir de "una selección de significados en virtud de leyes compositivas inveteradas que proceden [...] de la pintura tradicional y de la poética del teatro clásico" (Ramírez, 1997, p. 211). El discurso de los distintos cómics de esta etapa en la creación del autor, hacen buena esa máxima teórica en la que el relato en cómic se nutre de momentos que "son en realidad espacios [...] Entre los distintos espacios escénicos el dibujo crea equilibrios, correspondencias, compensaciones de líneas, formas y masas" (Altarriba, 1983, pp. 32-34). En relación a estos espacios, aunque a la viñeta se la identifica tradicionalmente como una unidad de tiempo, en su tesis doctoral sobre la bande dessinée (B.D.) francesa, Altarriba defiende la singularidad y centralidad del espacio en la historieta (1981, p. 11).

Esta galería de referencias, de elementos pictóricos y visuales alusivos a la historia del arte occidental son recursos específicos integrados en la propuesta estética y narrativa que ofrecen Altarriba y sus dibujantes. En este sentido, los guiños o citas veladas que pueden desentrañar claves o códigos del relato secuencial pertenecen a la competencia variable y 
a la competencia enciclopédica de cada lector (Eco, 1993, p. 84, 109) y a una iconicidad universalmente percibida "en la transmisión cultural de ciertos códigos perceptivos" (Ramírez, 1997, p. 203). La aportación de esta referencialidad muestra la enorme riqueza y la batería iconográfica de los imaginarios ideados por Altarriba y los dibujantes con los que trabaja. Sería reduccionista simplificar cuantitativa y cualitativamente el trabajo de estos autores, que ejemplifica hallazgos y exploraciones, diseñadas con un maravilloso aparato polisémico surgido entre el diálogo entre el guionista y los responsables gráficos. Al hacerlo, ahondan en una definición propuesta por el propio Altarriba en sus primeras aportaciones teóricas, y por la cual, el cómic vendría a ser una "serie de espacios que, conteniendo imágenes elaboradas manualmente y a menudo también textos relacionados con aquéllas de manera mayoritariamente no redundante, se yuxtaponen en el interior de una (varias) página(s) destinada(s) a la reproducción" (Altarriba, 1985, p. 56).

\section{En el principio: todos los colores del mundo}

Si tomamos la afirmación de Altarriba escrita para el epílogo del brillante álbum gráfico Detective, cuando pensamos en el ámbito de la representación o de la comunicación humana en el principio no fue la palabra, puesto que "la palabra sólo es el principio del lenguaje [...] mucho antes que el Verbo están todos los colores del mundo" (1991, p. 75). La elección temática del arte pictórico como vehículo narrativo ya es trazable en su visionaria tesis, en la que apuntaba no solo la importancia de las referencias, sino también la naturaleza singular del cómic como mosaico de citas:

La imagen, que puede proporcionar la identidad por medio de la sumisión a las referencias copiando fielmente la realidad, prefiere aquí como en todas sus utilizaciones creativas marcar una diferencia. Esa diferencia se convierte en la clave de la personalidad de la B.D. de que podrá ser distinta en la forma de presentar a sus personajes [...] con lo cual la referencia no queda burlada sino transformada por un tratamiento original [...] únicamente tendrá relación con su propio mundo gráfico, totalmente independiente de la realidad y de dónde lo insólito surge sin dificultades (Altarriba, 1981, p. 36).

En el caso de Altarriba, lo insólito parte ya de su lugar de trabajo. Frente a la centralidad creativa tradicional, marcada por Barcelona y Madrid, el artista viaja entre Vitoria y Zaragoza, reflejando de alguna manera la descentralización que se produce tras la restauración de la democracia en España en 1975. Puede parecer algo anecdótico, pero propició una efervescencia que consolidó propuestas desde la periferia obviando las pretensiones más comerciales de los dos polos de creación tradicionales, y generó un nuevo posicionamiento de colectivos, autores y artistas, que se vieron liberados de las imposiciones marcadas por críticos o gestores culturales desde las dos capitales culturales españolas. La transgresión o la vanguardia se difuminaban geográficamente y no eran patrimonio del dictado de unos pocos tótems o gurús, puesto que el cómic se consolidó como "un nuevo producto 
de los mercados editorial y artístico caracterizado por el aumento de publicaciones mensuales [...] cada una de ellas [eligió] su propia línea tanto a nivel temático como de expresión artística" (Lladó Pol, 2001, p. 12).

La sincronía entre una nueva manera de entender el cómic y los cambios políticos y sociales es admitida por el propio Altarriba:

España alcanzaba la mayoría de edad política, la historieta también se hizo adulta o, al menos, empezó a dirigirse mayoritariamente a un público adulto. Cambió por completo de piel, adoptó otros estilos, se recubrió con un grafismo más elaborado, exploró intrigas más complejas y reclamó la medalla de medio artístico (Altarriba, 2001, p. 17).

Como señala Francisca Lladó Pol (2018, p. 322), la muerte del dictador Francisco Franco supuso un antes y un después en lo que a lo largo de quince años (1976-1991) vendría a ser la producción en el cómic de vanguardia publicado en España. Un irrepetible momento para la historieta underground, a partir de las distintas publicaciones que aparecieron a finales de la década de los setenta y a lo largo de los ochenta y que dieron cabida a algunos de los creadores y de las propuestas más singulares que jamás tuvo el cómic hispánico ${ }^{6}$. Con una sensibilidad gráfica próxima a las propuestas estéticas de las corrientes de las artes plásticas contemporáneas, la historieta nacional supuso, como en otras manifestaciones culturales, un asombroso hervidero de creaciones sin parangón. Por su compromiso con otras formas de contar y de expresar autónoma y radicalmente secuenciales, el cómic de esos años, con la perspectiva del tiempo, se sitúa en parámetros de una libertad, de una potencia visual y textual nunca replicadas. Este ciclo de quince años vendría a ser análogo en el tiempo a la primera etapa de creación como guionista de historieta de Antonio Altarriba.

\section{Royo y Altarriba en busca del tiempo perdido}

La época que se extiende entre finales de los años setenta y durante los ochenta, hasta los primeros años noventa ${ }^{7}$, supone para la producción de Altarriba un momento de gran efervescencia cultural y exploración artística a medio camino entre su Zaragoza natal, de la que nunca se desvincula por asuntos familiares, y Vitoria, su ciudad de adopción por cuestiones laborales. Además de espacialmente, Altarriba también va a vivir en una disociación intelectual pues, mientras desarrolla el experimentalismo de la narración figurativa (Vilches, 2016, p. 63) debe ocuparse de su labor académica, que no academicista, como docente e investigador universitario de la Universidad del País Vasco (UPV). En su posición de guionista de cómics va a impulsar obras e iniciativas en las que compartirá créditos con el dibujante Luis Royo (Olalla, Teruel, 1954). La alianza creativa de ambos artistas es una de las páginas más brillantes del experimentalismo del cómic en español ${ }^{8}$. En los bulliciosos años ochenta, Altarriba se convierte en impulsor y agitador editorial con apuestas como la revista de estudios sobre el cómic Neuróptica (1983-1988); en comisario 
de exposiciones sobre cómic; y en responsable de algunas de las colecciones de historieta más importantes de la editorial Ikusager.

Desde esos primeros inicios como renovador de la historieta nacional, Altarriba y los dibujantes con los que colabora no eluden incursiones y referencias múltiples a imágenes plásticas precedentes de los artistas que más los han influido. Tal es el caso de El paso del tiempo, volumen recopilatorio de los trabajos con Luis Royo publicado en Norma Editorial en $2011^{9}$, edición de los trabajos que supusieron la estrecha colaboración de Altarriba y Royo entre 1977 y 1987. El propio Altarriba lo cuenta en el prefacio del libro: "durante casi una década viajé desde Vitoria, donde vivía, a Zaragoza para pasar los fines de semana, casi sin excepción, junto al tablero de dibujo de Royo" (Altarriba y Royo, 2011, p. 9). En ese ámbito, Royo y Altarriba aspiran a que la imagen fuera suficiente vehículo para la narración de la historia. Sus preocupaciones estéticas y estilísticas desembocaron en el Grupo Bustrófedon ${ }^{10}$, colectivo vanguardista de cómics surgido en Zaragoza. En esos inicios, Altarriba y Royo homenajean la pintura surrealista de René Magritte (1898-1967), constante a lo largo de muchas de las narraciones figurativas firmadas por Altarriba, un pintor que sintoniza con el cómic recurrentemente (Gasca y Mensuro, 2014, p. 281). Tal y como señala la Profesora Lladó Pol:

Al buscar el protagonismo de la narración, las obras de René Magritte resultaban idóneas ya que inducían a la mutilación de la realidad objetiva [...], por lo cual dibujante y guionista optaron por utilizar una única frase que se repite a lo largo del cómic hasta dieciocho veces: "Señoras y señores, la demostración que juntos vamos a realizar tenderá a mostrar algunas relaciones existentes entre las imágenes y las palabras" [...] Las referencias pictóricas son las vestimentas atemporales de obras como Le grand siècle, las esferas seccionadas de Le discours de la méthode y las nubes de Le empire des lumières junto a figuras metamorfoseadas que turban al espectador a la vez que lo llevan al propio subconsciente, para finalizar con una página igualmente inquietante propia de la pintura metafísica de Chirico con sus plazas desérticas y esculturas a ras del suelo (Lladó Pol, 2018, pp. 332-333).

La performance ejecutada por Magritte en la muestra Young Belgian Artists de la London Gallery (1937) inspira el relato "Sin Vención, con vencimiento" (2011, pp. 16-27), singular pieza secuencial en la que se juega con el lenguaje del cómic a partir de la liberación de unos bocadillos y de elementos como el hombre con bombín, peones de ajedrez, flores, frutas, esferas sonoras y diversas referencias a cuadros del pintor belga. Dentro de estos intertextos, Royo y Altarriba también recurren a las imágenes pictóricas metafísicas de Giorgio de Chirico, el apolíneo pensador de Rodin o incluso la silueta de Charlot, el célebre personaje creado por Charles Chaplin.

En "Autorretrato"11 (2011, pp. 28-37), guionista y dibujante se esfuerzan por articular un relato de espejos en blanco y negro que recurre en forma de flashback al género pictórico que le da título, representado con una enorme carga surrealista. Principalmente, en una estética deudora del artista neerlandés Maurits Cornelis Escher (1872-1972), y que enlaza, ahora en color, con el automatismo surrealista de la historieta "Mecánica"12 (2011, pp. 
38-47). Royo y Altarriba en sucesivos ejercicios de estilo en las obras fantásticas "Germinación” (2011, pp. 48-57). o "Dioptría" (2011, pp. 104-111). van a renunciar a cualquier recurso en forma de cartuchos o elementos de narración, al margen de la propia secuenciación de las imágenes, próximas al surrealismo más figurativo o al erotismo de "El grito" (2011, pp. 58-67), “O'clock" (2011, pp. 112-115) o “Autopsia” (2011, pp. 116-123). Y de nuevo, la cita de Escher en "Otoño" (2011, pp. 68-75) o las evocaciones de la fantasía procaz y caudalosa cercana a la mítica publicación francesa Métal Hurlant como "Hybris" (2011, pp. 76-85), "Lautreamont y el surrealismo" (2011, pp. 154-167)., "Neorama” (2011, pp. 168-171) y "El filo de la luna" (2011, pp. 172-173), pero con una radical capacidad para construir relatos secuenciales de enorme singularidad. En esta antología de los creadores aragoneses destaca también "La probable locura de Felicien Rops"13 (2011, pp. 86-103). La figura del pintor simbolista belga Felicien Rops (1833-1998) sirve a Altarriba para crear un relato de suspense que juega con el artículo científico como género narrativo y relato metaliterario y metartístico, impregnada del malditismo romántico del artista belga y sus aficiones ocultistas. La complicidad de las aportaciones gráficas de Royo, emulando el estilo esotérico de los grabados de Rops, resultan fundamentales.
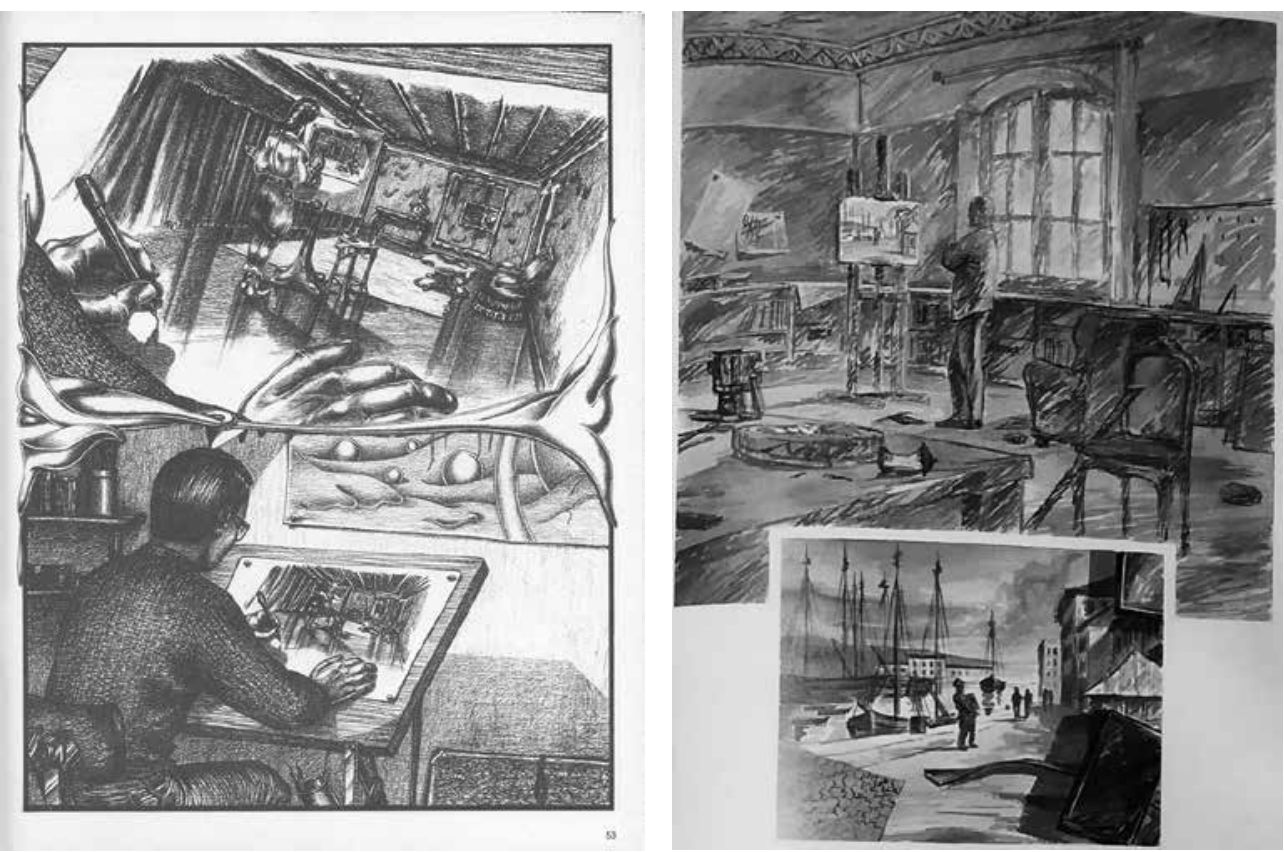

Figuras 1 y 2. Antonio Altarriba y Luis Royo. Autorretrato y El puerto de Gijón: modo de empleo. 
En el volumen recopilatorio sobresale una adaptación gráfica de la prosa de George Perec (1936-1982), libre traslación historietística (2011, pp. 128-151) de la novela La vie mode d'emploi (1978), transformando Altarriba el recurso oulipista del lipograma (no emplear una letra o varias en la escritura de un texto) de la literatura potencial de Perec en un lipocromo ${ }^{14}$ (prescindir de uno de los cuatro colores básicos por parte de Royo). "El puerto de Gijón: modo de empleo"15 (1987), traducción, adaptación y guión de Altarriba a partir de la novela de Perec y de la trama del personaje de Bartlebooth. Reinterpretado por Royo y Altarriba, la historia se convierte en una reflexión sobre la fugacidad - e incluso futilidad si se quiere- del arte, puesto que el protagonista invierte su fortuna en un proyecto vital parta pintar más de quinientos paisajes en acuarela, que terminaran convirtiéndose en la nada, aspiración final de Bartlebooth como artista y como ser humano.

\section{Compartir miradas: Altarriba et al.}

Al margen de la producción con Luis Royo, Altarriba va a emprender otras colaboraciones, no tan intensas pero igualmente fecundas, con otros dibujantes. Muchas serán piezas cortas, tal y como era habitual en la industria del cómic de la época. Son piezas pensadas sin afán de continuidad o sin posibilidad de alargarse. Muchos de estos relatos secuenciales son ensayos y potenciales ejercicios de creación que alimentarán la madurez de Altarriba como autor.

En esta línea, entre 1982 y 1983, Altarriba realiza los guiones para una serie llamada Cortocircuitos, con Strader (Manuel Estradera, Zaragoza, 1956). En el número 3 de la revista Rambla aparece "La puerta" (1982, pp. 29-32), una de estas historias cortas cuyo grafismo alterna la caricatura con elementos y personajes de gran realismo. Las referencias surrealistas en la obra de Altarriba adquieren un significado burlón con la creación de una pareja de singulares operarios, dedicados al mantenimiento de un complejo de sanitarios, que les proporcionan variadas alucinaciones, siendo éstas sus verdaderas motivaciones laborales. La inclusión de objetos como el retrete-teléfono, próximo a la irreverencia de La Fuente (1917), el celebérrimo "ready-made" de Marcel Duchamp, favorecen la cualidad innata para epatar desde la ironía escatológica. Otro tanto ocurre con secuencias en las que el lector puede distinguir a un gigantesco sembrador de llaves para sanitarios, cuya apariencia, con el cráneo rasurado y lo que parece un collar ritual al cuello, remite a un sacerdote oriental. Viñetas que conforman la interesante propuesta de los creadores zaragozanos, en una historieta tan hilarante como llena de imágenes de gran potencia visual.

Durante 1983, aparece la historieta "Eco de Mercurio" en los números 4 y 5 del fanzine vitoriano Octopus, publicación del colectivo del mismo nombre y que será la primera colaboración de Altarriba con el pintor e historietista Javier Hernández Landazábal (Vitoria, 1959). Realizada en blanco y negro, aglutina los trazos caricaturescos del protagonista y la versatilidad realista de Landazábal. En consonancia con este accidentado y lejano proceso de publicar en distintas publicaciones del sector y al hilo de la situación del noveno arte en España, Altarriba prosigue en su afán y realiza, junto a Samuel Aznar, dibujante y compañero de batallas en Bustrófedon, la historieta "Especulación" (1984, pp. 11-16), aparecida 
en la revista vitoriana Lux Daemoniorum. En la obra, junto con la bicromía en blanco y negro, se aprecian algunos de los caminos y exploraciones emprendidas por Altarriba con Royo. A partir de una secuenciación aliterativa, en la que el juego de la superposición y el reflejo suponen un papel esencial, sin la presencia de palabras, las tres primeras viñetas ocupan el espacio completo de la hoja. La propuesta es una suerte de rompecabezas en la que el rostro de un hombre alopécico, megaencefálico, escruta enigmáticamente al lector. El personaje lleva unos anteojos, en alusión a la acepción etimológica de lo especular vinculada al espejo, cuestión recurrente en la producción de Altarriba. El estilo limpio y conciso de Aznar presenta una profusión de espejos y reflejos articulando una lúcida reflexión sobre el paso del tiempo. Las últimas viñetas revelan sutilmente el memento mori que es este cómic, tan fugaz y evocador como tristemente lúdico.

En el año 1984 aparece también la historieta breve "Asepsia" (1984, pp. 47-50), con grafismo en color de Rafael Estrada. La influencia de Moebius puede parecer obvia en cuanto a la paleta de colores, y a ella se suman elementos que remiten a Giorgio de Chirico (esculturas decapitadas) y a H. R. Giger (bocas dentadas en articulaciones o abdómenes femeninos en atmósferas impregnadas de espesos vapores).

Ya en el ecuador de la década, Altarriba colabora de nuevo con Hernández Landazábal, en "El arte de la fuga"16 (1986). La historieta es una singular reflexión cuya narrativa adopta la forma de muñeca rusa sobre la ejecución artística. El relato pone de manifiesto el virtuosismo técnico en el dibujo y el coloreado del artista vitoriano en una breve narración que es una brillante y mordaz reflexión sobre el arte en general y el arte de la historieta en particular, jugando con las variadas posibilidades de la ejecución artística, traduciéndose ésta en tres tipologías de viñetas: horizontales, verticales y trapezoidales. La estética hiperrealista de trazas pop de Landazábal se yuxtapone al gusto surrealista de Altarriba, tres personajes pirandellianos en busca de autor que muestran en dichas tipologías de viñetas actos de creación artística que están imbricados entre sí: la ejecución del pianista Ladislao Laliena de las variaciones de Listz en un piano de cola Schimmel que vaga sin rumbo por el océano en una precaria balsa de madera con bidones; y el relato del músico que brota de una máquina de escribir, la Olivetti Lettera cuyas teclas golpea el escritor Feliciano Flumen a bordo de un globo aerostático a la deriva; a su vez la aventura del escritor es plasmada por el pintor Bruno Bramante que huye por el desierto en una moto, en el manillar del vehículo se encuentra adaptada su mesa de dibujo. El final de esta historieta diluye todo lo anterior y la creación -como en la trama de Bartlebooth en "El puerto de Gijón: modo de empleo"- está abocada a la disolución, encaminada a la a la nada. 

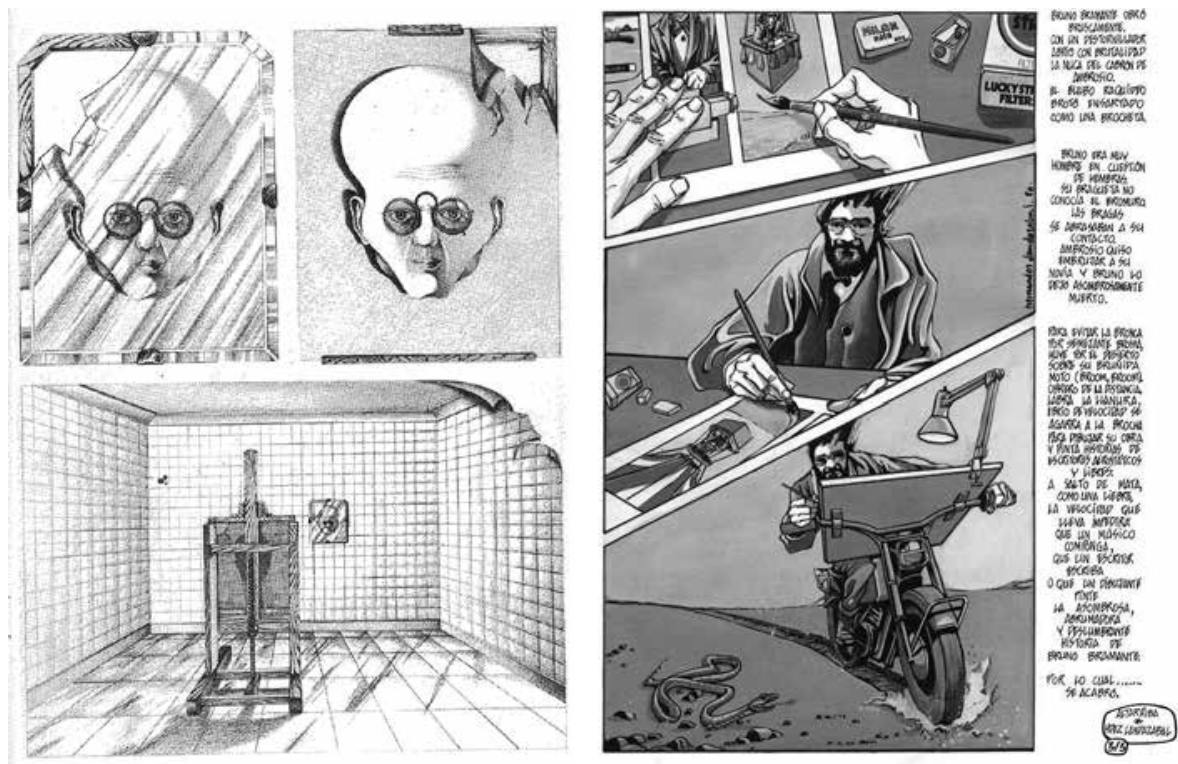

Figuras 3 y 4. Especulación y El arte de la fuga. Altarriba con Samuel Aznar y Hernández Landazábal.

La primera colaboración de Altarriba con la joven artista Patricia Albajar se materializa en "El cuento que nunca existió", publicado en el número 3 de Medios revueltos (1988), con guión de Altarriba y dibujos en blanco y negro de Albajar. Desde el intitulado con el retorcido subtítulo en paréntesis “(No existirá)", la historieta es una fábula fantástica, bufa y lisérgica, que juega con un corrosivo y ácido humor frente a los esquemas básicos de El Quijote, las sagas míticas germánicas, o los cuentos clásicos de los que se apropia, con referencias a la tradición decimonónica impulsada por Charles Perrault o los Hermanos Grimm. Albajar y Altarriba también parodian las odas patrióticas que invocan pasados nacionales. El sarcasmo llega al paroxismo con la recreación de Edipo y la esfinge en clave postmoderna. El protagonista es un sesudo intelectual con atributos del físico Stephen Hawking, que debe resolver el enigma de la esfinge, planteado en esta ocasión por el ogro feroz y el buitre voraz que protagonizan la historieta. El tema remite a la representación iconográfica del mito de Edipo tal y como lo abordaron en el XIX Jean-Auguste Dominique Ingres (1808) o Gustave Moreau (1864), y que llegó hasta finales del siglo XX a través de la nueva figuración pop del pintor italiano Valerio Adami (1980). El resultado final es una inversión de los relatos clásicos. Desde una perspectiva formal, la mayor parte de los bocadillos, los cartuchos y otros estilemas del lenguaje del cómic se diluyen o reinterpre$\tan$. Muchas de las viñetas se disuelven y definen de forma rupturista. Se compone así un 
relato secuencial que mezcla, lúdica e irónicamente, la propia trama con las iconografías precedentes.

En el año 1989, siguiendo el guión de Altarriba, aparece "Dos estados de una unión”, obra en la que Ricard Castells (1955-2002) se vale del color en una apuesta estética que hermana al artista catalán con el universo artístico de Alberto Breccia ${ }^{17}$ en el álbum colectivo Norte Sur. Los contrastes de la narración, ambientada durante la segunda mitad del siglo XIX, se articulan en torno a dos historias que convergen entre el esclavismo sureño y el abolicionismo defendido por los estados del norte de Estados Unidos que desembocaron en la Guerra de Secesión (1861-1865). De Breccia se percibe una continuidad en la capacidad de Castells para disolver la figura humana en la escenografía de las viñetas, con técnicas como la aguada, más propias de la pintura que de la ilustración o la historieta. Esta tendencia supone que los bocadillos de diálogo se diluyan en transparencias o en otras variables narrativas. A partir de técnicas mixtas (acuarelas, anilina, rotulador, ceras, guache, pastel, óleo, látex, acrílico, tinta china, lápiz, vinílicos, purpurina líquida y collage), el acabado híbrido de la historieta sumerge al lector en un relato secuencial de pesadilla, con influencia del expresionismo pictórico y mostrando un experimentalismo gráfico que, como apunta Jan Baetens, integra visualmente dos mundos diegéticos en los que la historieta transgrede desde el uso cromático del blanco o la disposición convencional de filacterias del cómic (1990, pp. 47-50).

De nuevo con Castells, Altarriba realiza un pequeño ensayo en relación a la pintura de Paul Delvaux (1897-1994). Este trabajo teórico se acompaña de un breve cómic complementario, en el que Altarriba y Castells plasman algunas de las obsesiones de Delvaux. La obra será publicada en $1990^{18}$ en el primer número de la revista hispanobelga Correspondance con el título "Paul Delvaux y su viaje al centro del espejo -El día que Paul Delvaux se convirtió en Otto Lidenbrock” (1990, pp. 29-34). En ambas piezas se reflexiona en torno a la vida y al arte, acudiendo a elementos recurrentes en la producción pictórica de Delvaux como los espejos, los reflejos, las apariencias, y la fugacidad de la propia existencia. Ensayo y cómic señalan representaciones intertextuales de naturaleza órfica, apuntando el tema de la muerte y aludiendo al juego metatextual de Delvaux en la figura de Otto Lidenbrock, personaje literario del Viaje al centro de la tierra (1864) de Jules Verne, convertido en un alter ego del propio pintor en más de media docena de sus cuadros. La breve historieta contextualiza las reflexiones de Altarriba y se convierte en un paseo por algunas de las filias artísticas más recurrentes en el autor zaragozano. En esta línea de citas referenciales, se alude al propio Delvaux y a algunas de sus obras, como El museo Spitzner (1943), pintura del gabinete anatómico itinerante de monstruosidades. El cómic de Castells y Altarriba menciona a personajes a través de un periódico con noticias relacionadas con los pintores James Ensor, Giorgio de Chirico y René Magritte. Como hemos visto, las referencias a estos dos últimos han constituido parte esencial de la obra de Altarriba durante esta etapa. Será la misma línea que podemos observar en Detective (1991), obra en color con dibujo de Javier Hernández Landazábal. En esta ocasión, el motivo de su nueva colaboración es el encargo del dibujante para que Altarriba realice el catálogo expositivo de una muestra de sus cuadros hiperrealistas. A partir de un corpus precedente de más de treinta cuadros, con la complicidad del propio Hernández Landazábal ${ }^{19}$, Altarriba idea diferentes relatos unidos por dos denominadores comunes: un detective que es el hilo narrativo de la fic- 
ción, y los distintos casos de investigación en los que se ve envuelto por su profesión como investigador. Intrigas y misterios que tienen al arte como motor y materia del relato. De esta manera, Altarriba pasea con dinamismo por distintos referentes pictóricos, sumergiéndose el lector en tramas articuladas a partir de los cuadros de Hernández Landazábal y su referencialidad directa a las iconografías de Piet Mondrian, René Magritte, Jorge Oteiza, Eduardo Chillida o el mismísimo Georges Prosper Remi "Hergé". Altarriba y Landazábal componen una singular y sugerente obra que mantiene su vigencia por medio de juegos metalingüísticos y múltiples referencialidades en una historieta adelantada a su tiempo. Merece una revisión por su propuesta seductora, llena de pistas y equívocos que homenajea -al tiempo que parodia- las narraciones del género negro.
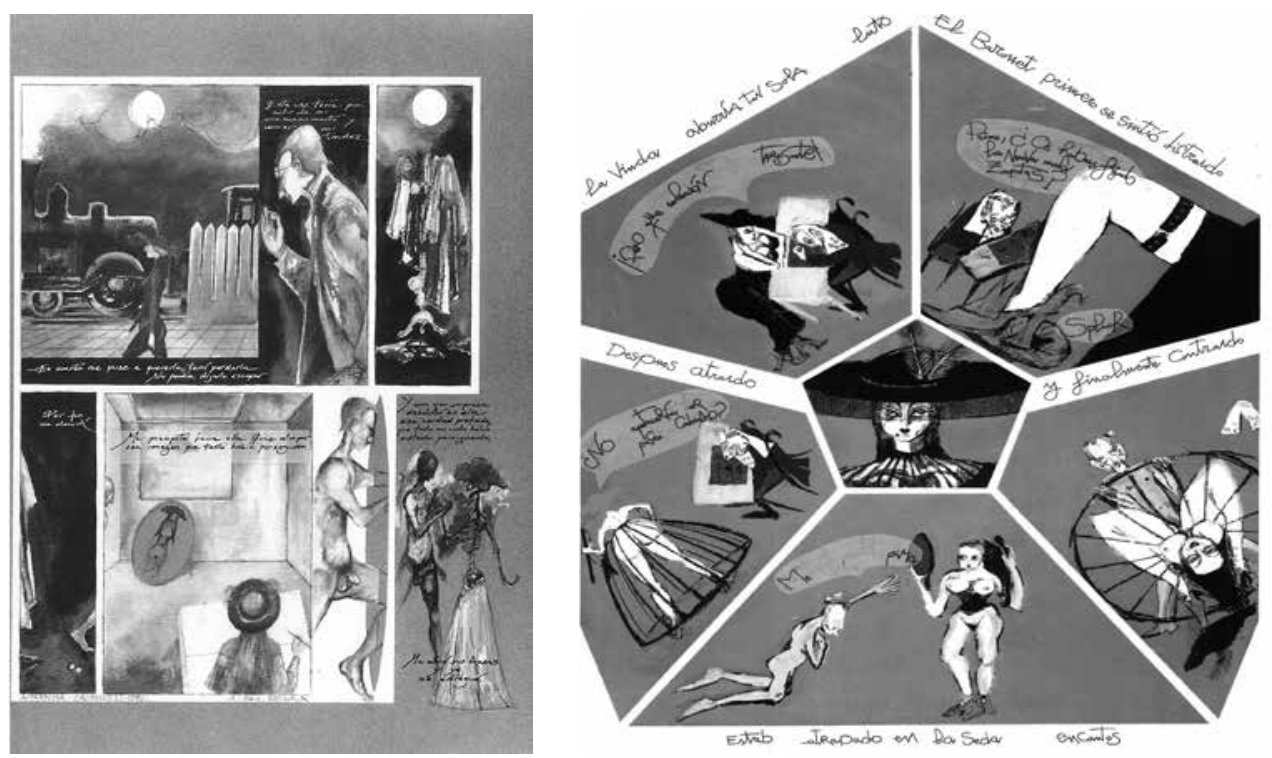

Figuas 5 y 6. Paul Delvaux y su viaje... y El arañazo. Altarriba con Ricard Castells y Patricia Albajar.

En 1991 se produce la segunda colaboración de Altarriba con Patricia Albajar ${ }^{20}$. En este caso sumergiendo al lector en el color y en el dolor, pues en "El arañazo" se intercalan la fuerza poética de la estética de Patricia Albajar con la intensa irreverencia, la mordacidad y la ironía de un Altarriba que ha ido perfeccionando su voz y su oficio como autor y narrador de historias. Altarriba, muy dado a los juegos etimológicos y a los sentidos polisé- 
micos, dispone en "El arañazo", ya desde el título, algunos sesgos del relato de esta singular y atractiva historieta, en la que permanece una vocación experimental. El protagonista es el peculiar Baronet de la Crisalide, aficionado a la entomología, actividad en la que parece volcada su ascética vida. Su colección de insectos parece ser su motor vital hasta que aparece su prima, la Marquesa de Tarentoile, que debido a su luto como viuda se refugia en la solariega vivienda de De la Crisalide. El Baronet se siente atraído por la mujer, en una relación con tintes sadomasoquistas que marcará su decadencia final tras el retorno a París de la Marquesa.

Altarriba retoma temáticamente el surrealismo y estéticamente, el grafismo de Albajar presenta una paleta pictórica de gran expresividad en la que los ocres y los tonos cálidos subrayan un devenir narrativo de pesadilla, "delirios" que se nutren del expresionismo y concretamente de pintores como Otto Dix, George Grosz o James Ensor. En esta historieta sobresale por composición e impacto en el relato, una página completa, una viñeta-secuencia que juega con la distribución pentagonal. De una hornacina central, también un pentágono, conteniendo el retrato de la Marquesa surgen a su vez cinco viñetas que son trapecios isósceles que al tiempo articulan un nuevo pentágono, idealización secuencial de una telaraña cuyas juntas y laterales superiores en blanco funcionan de cartuchos narrativos e informativos para el lector. Las mencionadas viñetas dispuestas de forma pentagonal con fondos rosas neutros, siguen la estética del retrato central, componiendo simultáneamente un retablo geométrico, en el que se sintetiza el proceso de seducción de la Marquesa y cómo el Baronet cae presa de sus encantos en lo que será una espiral obsesiva de autodestrucción. El Baronet, tras la placida práctica que le proporciona coleccionar insectos, encuentra en los placeres carnales que le ofrece su prima la Tarantoile, un camino que le conducirá a una resolución tan fatalista como la que prefigura la tela de araña tejida y pergeñada por la Marquesa, una auténtica viuda negra, letal arácnido para sus víctimas, en este caso operando como metáfora del abandono y el olvido.

La situación del cómic en España entrada la década de 1990 dará paso a un contexto cada vez más precario dentro de la industria, provocando un receso en la actividad de Altarriba en su labor como guionista de cómics. Serán otros los lugares en los que expresarse hasta la llegada de nuevas estructuras, más propicias para los autores a principios del siglo XXI, un paréntesis en la producción gráfica de Altarriba que llega hasta la publicación de Amores Locos (2005) junto a la dibujante Laura Pérez Vernetti.

\section{Para una conclusión}

La riqueza teórica y artística de la obra de Altarriba justifica una mayor atención por parte de la academia a los estudios de cómic. Su trabajo es un punto de partida del que parten multitud de caminos, llenos de intersecciones. A través de su estudio comprendemos que las más variadas manifestaciones artísticas, desde la escultura, a los tapices, pasando por las vidrieras, la cerámica o la pintura, han recurrido a secuencias narrativas más allá de su acabado o de sus virtudes estéticas o plásticas (Altarriba, 2011, p. 10). Desde el estudio de Altarriba se comprende que los autores de historieta no ejercen la apropiación de temá- 
ticas ni de técnicas. El acervo, el equipaje iconológico de Altarriba y de los dibujantes con los que colabora en este primer periodo se yuxtapone de forma natural. En ese fructífero diálogo, se encuentran muy presentes pintores como Magritte, Escher, De Chirico, Rops y Delvaux, que tendrán un correlato posterior, en mayor o menor medida, en las narraciones gráficas de Altarriba a partir de 2005.

En su labor como crítico y creador, todas las experiencias de Altarriba en los distintos ámbitos en los que ha desarrollado su trabajo han resultado enriquecedoras. Puesto que como afirma el propio interesado:

Estamos hablando de actividades afines. Literatura y cómic, crítica y docencia son sólo modalidades para practicar y entender los engranajes narrativos. $\mathrm{Me}$ parece que el autor que se interna en medios y prácticas diferentes se enriquece y que los logros en un campo se trasladan a otro. De hecho, creo que el autor que sólo lee y hace cómic empobrece sus recursos. Por el contrario, se resplandece en la diversidad, incluso en la divergencia (Cuestionario online enviado y respondido por Antonio Altarriba, 08/03/2020).

Una divergencia muy presente en los inicios de su ya longeva y sin duda prolífica carrera. Desde entonces, Altarriba tiene muy claro que las tareas que realizan los creadores de un cómic suscitan "un elevado grado de implicación entre el autor y su obra. No es de extrañar por lo tanto que se infiltran con facilidad las «veleidades artísticas» que relativizan enormemente su consideración como «media»". A este respecto, Altarriba señala que "Las frecuentes fetichizaciones proporcionan incluso un terreno abonado para un mercado especulativo de originales o para fórmulas de venta propias de "obra gráfica»" (Altarriba, 1985, p. 46). Gran parte de lo expuesto por Altarriba hace más de treinta años sigue vigente. Un proceso al que contribuyeron tanto el creador aragonés como sus compañeros de viaje. Juntos cambiaron la percepción de la historieta, fortalecieron su consideración crítica, su capacidad subversiva, vanguardista, y se situaron en los márgenes. Fueron un grupo de guionistas y dibujantes que durante los años venideros revitalizaron la historieta en el contexto hispánico. El estereotipo de unos historietistas sometidos supuestamente a las necesidades de la reproducción masiva, y condicionados por ello a un lenguaje al servicio de consideraciones industriales, parece ya un discurso superado, cuestiones relativas al cómic cuyo encaje en el ámbito de los estudios de humanidades y ciencias sociales parece cada vez más integrado.

En este repaso a la primera etapa de Altarriba es palmaria la versatilidad del creador aragonés para trabajar con diferentes dibujantes y colaborar en plasmar sus distintas sensibilidades artísticas. La interacción con los artistas visuales con los que ha trabajado Altarriba ha supuesto conciliar y nutrirse de la sensibilidad y el imaginario del guionista y sus dibujantes.

Entre Detective (1991) y Amores Locos (2005), Altarriba no recibe ninguna propuesta para realizar guiones de cómic, un paréntesis impuesto por la crisis del cómic europeo y particularmente, del cómic español. Tras el cierre de las revistas, eran escasos los autores que podían publicar y más si se piensa que el concepto y el formato de novela gráfica aún no se habían desarrollado. El mismo Altarriba pensaba que esa crisis acabaría o marginaría 
definitivamente al cómic, pero lo que ocurrió fue una redefinición de la industria y la consolidación de un nuevo espacio editorial y creativo de enorme transcendencia, cuya importancia creativa y comercial es indiscutible.

\section{Notas}

1. Los autores quieren agradecer la inestimable ayuda y colaboración de Antonio Altarriba en el desarrollo de esta investigación. Su colaboración y generosidad ha sido decisiva para su realización.

2. https://orcid.org/0000-0003-3445-1304

3. https://orcid.org/0000-0002-4962-2500

4. La artista fotográfica Pilar Albajar, mujer de Altarriba, lleva colaborando artísticamente con él desde hace tres décadas. Artífices de algunas imágenes tan perturbadoras como sugerentes, muchas de inspiración surrealista. Estas obras, tan evocadoras como epatantes, han merecido reconocimiento, fundamentalmente fuera de España, refrendado por la exhibición de su trabajo en centenares de exposiciones colectivas e individuales. Sin duda, el trabajo de ambos apunta una necesaria revisión y estudio dentro del contexto de la fotografía de composición y de los fotomontajes.

5. En los años noventa por la situación del cómic español, se centra en la prosa literaria, fundamentalmente en el género erótico.

6. En el periodo "entre 1977 y 1986 el mundo editorial español contempló [...] la irrupción en el mercado de unas cincuenta publicaciones periódicas basadas de forma casi exclusiva en la historieta [...] Los efectos de esta situación se revelaron devastadores a medio plazo y la mayoría de estas empresas tuvieron una muy breve duración" (Altarriba, 2001, p. 320).

7. "La década de los noventa conoció un reajuste a la baja tanto de las expectativas comerciales como de las ambiciones estéticas y narrativas" (Altarriba, 2001, p. 18).

8. En su labor como guionista, Altarriba tiene muy clara la potencialidad del arte secuencial, valora el trabajo que puede aportar un buen dibujante en la puesta en escena y, en esencia, considera que a través de la imagen en la historieta se puede transmitir y matizar lo no verbal con un alto grado de fidelidad narrativa (en Vilches, 2016, p. 70), pero aunque suele aportar numerosas soluciones visuales, Altarriba cree en la capacidad del dibujante para expresar su sello personal y artístico (en Vilches, 2016, p. 73).

9. Altarriba señalaba en la introducción que su trabajo con Royo paso desapercibido (2011, p. 10). Con la perspectiva crítica contemporánea resulta sorprendente dicha omisión. La publicación del grueso de la colaboración apareció separadamente en publicaciones como 1984, Comix Internacional, Rambla y El Víbora.

10. Conocidos desde la infancia, Altarriba y Royo afianzaron su alianza militando en el Colectivo Zeta, grupo de creación historietístico zaragozano en el que militaban Azagra, Gregorio, Lahuerta, Marcos, Mastral, Joven, Rojo y Soteras y tras las polémicas surgidas en torno a los tres números de Zeta, algunos de sus miembros pasan a impulsar a partir de 1979, Bustrófedon, revista del mismo nombre que el grupo que etimológicamente alude a "como ara el buey", escritura de izquierda a derecha y la subsiguiente de derecha a izquier- 
da. El grupo con Altarriba y Royo, contaría también con Samuel Aznar, Strader, Carlos Castillo, Ricardo Joven, Víctor Lahuerta y Manuel Mastral, tal y como se apunta en el primer número de la revista Neuróptica, impulsada por los componentes de Bustrófedom y liderada por el propio Altarriba. El valor de lo periférico distinguía al Grupo Bustrófedon en Zaragoza frente a los centros de producción en las tradicionales metrópolis de la creación artística del país.

11. Publicado originalmente en el número 4 de la revista Rampa (1984, pp. 50-58).

12. Publicado originalmente en el número 2 de la revista Rampa (1984, pp. 49-56).

13. Publicado originalmente en el número 3 de la revista hispanobelga Correspondance en el año 1993.

14. Altarriba lo explica así: "Llevamos el lipograma, una traba literaria que consiste en escribir sin utilizar un número determinado de letras, al mundo del dibujo y del color y así inventamos el lipocromo. El juego consiste en colorear eliminando uno de los cuatro colores básicos. En nuestra historia empezamos en blanco y negro (lipocromo en azul, rojo y amarillo), en la siguiente página añadimos el amarillo (lipocromo en azul y rojo), en la tercera el rojo (lipocromo en azul) y en la cuarta tuvimos la cuatricromía completa. La segunda parte de la historia es lipocromía descendente, quitando un color en cada página hasta llegar al blanco y negro" (Cuestionario online enviado y respondido por Antonio Altarriba, 08/03/2020).

15. La pieza apareció originalmente en el libro Sobre literatura potencial (1987, pp. 124147), actas del Encuentro sobre literatura potencial celebrado en Vitoria (diciembre de 1985), evento y volumen (publicado por la Editorial de la Universidad del País Vasco en 1987) coordinados por el propio Altarriba.

16. El evasivo título, ni temática ni estéticamente, tiene analogía alguna con la novela gráfica El arte de volar (2009) que firmará el guionista años después con Kim.

17. Compartiendo precisamente Castells y Altarriba créditos en el álbum con el mismo Breccia.

18. Poco después aparecerá publicado de nuevo en el número 2 de la revista Naturaleza y Abstracción con el título de "Paul Delvaux y la enfermedad de los espejos. De Paul Delvaux y de su viaje al centro del reflejo" (1991, pp. 54-60).

19. La obra de Landazábal y su aportación desde la corriente hiperrealista se puede sintetizar en un aforismo de su web personal: "revisión de la historia del arte desde una re-lectura del arte crítico, escéptico o irónico; nunca didáctico ni pedagógico” (http://www. hernandezlandazabal.com/ingles/empie.htm).

20. La incipiente carrera de Patricia Albajar (1968-2013) en la historieta recibió el espaldarazo de la exposición Nuevas Viñetas 1991, la artista oscense compartirá cartel con otros doce jóvenes creadores y otra parte de la exhibición contaría con consagrados artistas gráficos como Dave McKean y Laura Pérez Vernetti-Blina (Madrid Gutiérrez, 2016, pp. 426-427). La exposición se celebró en el otoño de 1991 en el Museo Español de Arte Contemporáneo de Madrid, organizada por el Instituto de la Juventud y el Ministerio de Asuntos Sociales, el comisario de la muestra fue Felipe Hernández Cava, celebre guionista y crítico del cómic nacional, siendo responsable junto a Manuel Ortuño de la publicación Medios Revueltos, revista donde se produce la primera publicación de una historieta de Albajar con guión de Altarriba. 


\section{Bibliografía}

Albajar, P. y Altarriba, A. (1988). "El cuento que nunca existió”. Medios revueltos, no 3, pp. 86-91.

Albajar, P. y Altarriba, A. (1991). “El arañazo”. Revista Injuve, extra no 2, Nuevas viñetas 1991.

Altarriba, A. (1981). La narración figurativa. Acercamiento a la especificidad de un género a partir de la Bande Dessinée de expresión francesa. Extracto mecanuscrito de la tesis doctoral: Valladolid.

Altarriba, A. (1983). "Características del relato en el cómic”. Neuróptica. Estudios sobre el cómic, no 1 , pp. 9-38.

Altarriba, A. (1985). "La crítica de cómic. Intento de examen de conciencia”. Neuróptica. Estudios sobre el cómic, no 3, pp. 34-57.

Altarriba, A. (2001). La España del tebeo. La historieta española de 1940 a 2000. Madrid: Espasa Calpe.

Altarriba,A. (2011). “Introducción sobre el origen, evolución, límites y otros debates teóricos en torno a la historieta”. ARBOR. Ciencia, Pensamiento y Cultura, no Extra 2, pp. 9-14.

Altarriba, A. y Aznar, S. (1984). “Especulación”. Lux Daemoniorum, no 5, pp. 11-16.

Altarriba, A. y Castells, R. (1990). "Paul Delvaux y su viaje al centro del espejo - El día que Paul Delvaux se convirtió en Otto Lidenbrock". Correspondance, no 1, pp. 29-34.

Altarriba, A. y Estrada, R. (1984) “Asepsia”. Rambla, no 17, pp. 47-50, Barcelona: Ed. García-Beá.

Altarriba, A. y Hernández Landazabal, J. (1986). “Ihesaren artea”, Habe, no 99, pp. 44-46. Edición en castellano: "El arte de la fuga", encarte en Texture, no 1 (1989).

Altarriba, A. y Royo, L. (2011). El paso del tiempo. Barcelona: Norma Editorial.

Altarriba, A. y Strader (1982). “La puerta”. Rambla, no 3, pp. 29-32, Barcelona: Ed. García-Beá.

Baetens, J. (1990). “Blanco sobre negro”. Revista Texturas. Nuevas Dimensiones del Texto y de la Imagen, núm. 1, pp. 44-51.

Beaty, B. (2012). Comics versus art. Toronto: University of Toronto Press.

Castells, R. y Altarriba, A. (1989). “Dos estados de una unión”. En Breccia, Aberto et al. Norte Sur, pp. 51-60. Vitoria: Ikusager Ediciones.

Eco, U. (1993). Lector in fabula. La cooperación interpretativa en el texto narrativo. Barcelona: Lumen.

Madrid Gutiérrez, M.D. (2016). Literatura e imagen en el cómic: Laura Pérez Vernetti-Blina. Tesis doctoral, Madrid: Universidad Complutense. Disponible en: https://eprints.ucm. es/39980. [Consultada el 09/03/2020].

Gasca, L. y Mensuro, A. (2014). La pintura en el cómic. Madrid: Cátedra.

Hernández Landazábal, J. y Altarriba, A. (1991). Detective. Vitoria: Ikusager Ediciones.

Lladó Pol, F. (2001). Los cómics de la Transición (El boom del cómic adulto 1975-1984). Barcelona: Ediciones Glénat.

Lladó Pol, F. (2018). "Apropiaciones y pertenencias. Citas pictóricas en el cómic español de los ochenta". Cuadernos de Arte de la Universidad de Granada, 49, 321-341.

Rajewsky, I. (2005). "Intermediality, Intertextuality, and Remediation: A Literary Perspective on Intermediality”. Intermédialités, 6, pp. 43-64.

Ramírez, J.A. (1997). Medios de masas e historia del arte. Madrid: Cátedra. 
Vilches, Gerardo (ed.) (2016). El guión de cómic. Barcelona: Diminuta editorial.

\begin{abstract}
Antonio Altarriba's first years as a comic creator are essential to understand some of the best narrative and aesthetic findings of Spanish contemporary comics. Altarriba's production between 1977 and 1991, in collaboration with many different graphic artists, reflects some of the aesthetic obsessions and references of art history in the early work of the author. During this period, he will build a very fertile, creative and suggestive imaginary. This research traces Altarriba's influences and expands the study of his little-known earliest work. In doing so, it points out some of his authorial marks, which have established Altarriba as one of the most outstanding authors of Spanish contemporary graphic narration.
\end{abstract}

Keywords: Antonio Altarriba - Spanish comic - painting - graphic novel - Bustrófedon Group.

Resumo: Os primeiros anos como criador de quadrinhos do Antonio Altarriba são essenciais para compreender alguns dos melhores achados narrativos e estéticos dos quadrinhos espanhóis dos finais do século XX. Ademais, a produção do Altarriba entre os anos 1977 e 1991, em colaboração com diversos desenhistas, reflete algumas das obsessões estéticas e das impressões sobre a história do arte na produção temprana do autor. Será o início da construção dum imaginário próprio tão fertil como sugerente. Esta investigação rastreja essas citas e amplia o estudo do corpus sequencial de Altarriba, para assinalar algumas das chaves que tem contribuído a marcar ele como um dos autores espanhóis mais destacados da narração gráfica contemporánea.

Palavras chave: Antonio Altarriba - quadrinhos - pintura - narração figurativa - Grupo Bustrófedon.

[Las traducciones de los abstracts fueron supervisadas por el autor de cada artículo] 